surves of variable stars of the Algol type. S. Antlize has usually been regarded as belonging to this class, and is specially interesting on account of its short period of $7 \mathrm{~h} .46 .8 \mathrm{~m}$., and because it is said to retain its full brightness for less than half its period, this last peculiarity being opposed to the probability of the variation being due to a dark eclipsing body. On constructing a curve from a series of $I 77$ measures, the conclusion is that S. Antlix is not a star of the Algol type, but its light is constantly changing, and that it should rather be classed among the variables of the $\delta$ Cephei or $\eta$ Aquilæ type. An interesting feature of the light curve for this star is that the increase of light is slower than the diminution. As this ratio $(0.62)$ in most other short-period variables is from $0^{\circ} 20$ to $0^{\prime} 33$, there seems reason for dividing the two classes.

The $\operatorname{star} \beta$ Lyrie is commonly regarded as a variable of short period of the same class as the above. "Observations of its spectrum, however, show that two or more bodies, revolving round each other, are present. The light curve found by Argelander may be closely represented by assuming that the primary minimum is caused by the eclipse of the brighter body by the fainter, and the secondary minimum by a similar eclipse of the fainter body by the brighter. This star should therefore be taken from the class of ordinary short-period variables and included among the stars of the Algol type." Lockyer finds, however, that there is evidence of greater complication in the system; and the theory of eclipses alone fails to account satisfactorily for the velocities in the line of sight which are obtained from the measurements of photographs of the spectrum of the star.

\section{AWARD AND PRESENTATION OF THE RUMFORD PREMIUM.}

IN conformity with the terms of the gift of Benjamin, Count Rumford, granting a certain fund to the American Academy of Arts and Sciences, the Academy is empowered to make, at any annual meeting, an award of a gold and silver medal, being together of the intrinsic value of three hundred dollars, as a premium to the author of any important discovery or useful improvement in light or in heat, which shall have been made and published by printing, or in any way made known to the public in any part of the continent of America, or any of the American islands; preference being always given to such discoveries as shall, in the opinion of the Academy, tend most to promote the good of mankind.

At the annual meeting of 1885 , the Academy awarded the Rumford premium to Thomas Alva Edison for his investigation in electric lighting, and the presentation of the medals took place at the meeting of May $13,1896$.

Vice-President Goodale, in presenting the medals, made the following remarks :-

"It would be highly presumptuous for one whose knowledge of physics is of the most elementary character to occupy the time of the Academy by any statement of his own in conveying these medals. Happily such a course is unnecessary. The Chairman of the Rumford Committee has placed at our command a brief statement which makes clear the ground of the award.

" The Rumford Committee voted, June 22, I 893 , that it is desirable to award the Rumford medal to Thomas Alva Edison in recognition of his investigations in the field of electric light ing, and they confirmed this vote on October 9,1893 , in the following words: "Voted for the second time to recommend to the Academy that the Rumford medal be awarded to Thomas Alva Edison for his investigations in electric lighting.'

"The Committee reached the conclusion expressed by these votes after long deliberation and after careful sifting of all the evidence which was at their disposal in regard to Mr. Edison's clain for priority in the construction of the incandescent lamp, the conception of the central lighting station together with the multitude of devices, such as the three-wire circuit, the disposition of the electric current feeders, and the necessary methods for maintaining the electric potential constant.

"The Committee felt that they could not decide upon Mr. Edison's claim for priority in any particular invention in this new industry. Indeed, Courts of Law, after prolonged litigation, have found it difficult to decide how far Mr. Edison was in advance of contemporary workers. The task given to the Rumford Committee to decide who is most worthy of the Rumford medal, especially in the field of the application of electricity for the production of light and heat, is not an easy one. The number of investigators is now so large that it is no longer possible, in general, for one man to claim to be the first to apply electricity to a new field. The successful application is the result of many minds working on the same problem. Although the Committee did not feel justified in expressing the opinion that Mr. Edison invented the incandescent carbon filament lamp, or that he was the first to arrange such lamp in multiple on the circuit, thus producing what is popularly termed a subdivision of the electric light, or that the Edison dynamo had greater merits than the machine of Gramme and Siemens and others; still, they are convinced that Mr. Edison gave a great impulse to the new industry, and that he was the first to successfully instal a central electric lighting plant with the multitude of practical devices which are necessary. They believe that this impulse was due to his indefatigable application, to his remarkable instinct in whatever relates to the practical application of electric circuits, and to his inventive genius. They, therefore, have unanimously recommended to the Academy to bestow the Rumford medals upon him, feeling that the work of Mr. Edison would especially appeal to the great founder of the medals-Count Rumford-if he were living.

"The Academy has accepted the report of the Rumford Committee, and has voted to confer the gold and the silver medal upon Mr. Edison. The recipient finds it impossible to be present at this meeting of the Academy, and has requested Prof. Trowbridge to act as his proxy and to receive the medals for him.

"In the name of the Academy, I beg you, Prof. Trowbridge, to accept the charge of conveying these medals to Mr. Edison's hands. It would be most ungracious for us who are assembled in this room, which is flooded by this steady and brilliant electric light, to withhold our personal thanks for what Mr. Edison's investigations and practical activities have done for us all. And, hence, I may venture to say that our thanks and all good wishes are to be conveyed with the Rumford medals."

Prof. Trowbridge replied as follows :-

"Mr. President, and gentlemen of the Academy, I accept the medals for $\mathrm{Mr}$. Edison; and at his request I wish to express his deep sense of the great honour the Academy has conferred upon him. His work in the field of electric lighting has been the subject of prolonged litigation, and at times he has had doubts, in reading the opinions of learned experts, whether his work has been original, or whether he had really contributed anything to the world's progress. The recognition of his labours by the American Academy iof Arts and Sciences, regarded by Count Rumford in his gifts as the coequal of the Royal Society of London, is, therefore, especially grateful to him. Acting as his proxy, I thank the members of the Academy for the distinction which they have, by their votes, conferred upon him."

\section{CAUSES OF DEATH IN COLLIER EXPLOSIONS.}

A REPORT, by Dr. John Haldane, on the causes of death in colliery explosions, with special reference to the Tylorstown, Brancepeth, and Micklefield explosions, was published in a Blue-book a few days ago. The report contains a vast amount of valuable information on the composition of after-damp, the action on men and lights of the gases present in, or mixed with, after-damp, the action of after-damp, heat and violence, along the track of an explosion, the distribution of after-damp and other gases in a mine after an explosion, the distribution of smoke in underground fires, the positions at which bodies are found after an explosion, and the means of saving life in colliery explosions and fires. To understand the dangers to life after a colliery explosion, and the possibilities of escaping these dangers, it is necessary to have a clear idea of the action, both on men and lamps, of the gases which are likely to be present in the air of the mine. These gases, so far as is known, are carbon dioxide, carbon monoxide, nitrogen, fire-damp, and sulphurous acid. Oxygen may be deficient or absent. Dr. Haldane discusses the effects of these gases seriatim, and the information he brings together, as well as his own careful observations, should be valued by colliery managers, while it will certainly interest chemists and physiologists.

In the case of the Tylorstown explosion, which, Dr. Haldane says, was evidently propagated through the three pits by coal-dust, fifty-seven men were killed. Of this number fifty-two, or 9I

NO. I 392 , VOL. 54] 